\title{
Long-distance transport of Gibberellic Acid Insensitive mRNA in Nicotiana benthamiana
}

\author{
Haiyan $\mathrm{Xu}^{1,2,4}$, Reika Iwashiro ${ }^{1}$, Tianzhong $\mathrm{Li}^{3}$ and Takeo Harada ${ }^{1,2^{*}}$
}

\begin{abstract}
Background: The Gibberellic Acid (GA) signal is governed by the GAl (Gibberellic Acid Insensitive) repressor, which is characterized by a highly conserved N-terminal DELLA domain. Deletion of the DELLA domain results in constitutive suppression of GA signaling. As the GAl transcript is transportable in phloem elements, a $\Delta$-DELLA GAI (gai) transgenic stock plant can reduce the stature of a scion through transport of gai mRNA from the stock. However, little is known about the characteristics of a scion on a gai stock.

Results: Arabidopsis $\Delta$-DELLA GAl (gai) was fused with a T7 epitope tag and expressed under the control of a companion cell-specific expression promoter, Commelina yellow mottle virus promoter (CoYMVp), to enhance transport in the phloem. The CoYMVp:Atgai-T7 (CgT) transgenic Nicotiana benthamiana exhibited a dwarf phenotype and lower sensitivity to GA enhancement of shoot stature. A wild-type (WT) scion on a CgT stock contained both Atgai-T7 mRNA and the translated product. Microarray analysis to clarify the effect of the CgT stock on the gene expression pattern in the scion clearly revealed that the WT scions on CgT stocks had fewer genes whose expression was altered in response to GA treatment. An apple rootstock variety, Malus prunifolia, integrating CoYMVp:Atgai moderately reduced the tree height of the apple cultivar scion.

Conclusions: Our results demonstrate that Atgai mRNA can move from companion cells to sieve tubes and that the translated product remains at the sites to which it is transported, resulting in attenuation of GA responses by reducing the expression of many genes. The induction of semi-dwarfism in an apple cultivar on root stock harbouring Atgai suggests that long-distance transport of mRNA from grafts would be applicable to horticulture crops.
\end{abstract}

Keywords: GAl, mRNA, Transport, Grafting, Dwarf, Phloem

\section{Background}

The importance of gibberellins (GAs) to angiosperm growth regulation has been demonstrated by the phenotype of GA-deficient mutants. The GA-deficient Arabidopsis thaliana ga1-3 mutant that lacks ent-kaurene synthetase A, an enzyme in the GA biosynthesis pathway, exhibits a characteristic severe dwarf phenotype [1]. Mutants such as ga13 are GA-sensitive dwarf mutants that have been observed in a number of different plant species and typically carry recessive mutations that reduce the activity of GA biosynthesis enzymes [2]. Further molecular characterization of

\footnotetext{
* Correspondence: tharada@cc.hirosaki-u.ac.jp

${ }^{1}$ Faculty of Agriculture and Life Science, Hirosaki University, Hirosaki 036-8561, Japan

${ }^{2}$ The United Graduate School of Agricultural Sciences, Iwate University, Morioka 020-8550, Japan

Full list of author information is available at the end of the article
}

various GA response mutants led to the discovery of the GID1 (GIBBERELLIC INSENSITIVE DWARF1) and DELLA proteins, which are key components of the molecular GAGID1-DELLA mechanism that enables plants to respond to GA [3]. Genetic and molecular studies have identified the GA receptors and several positive and negative components of the GA signaling cascade $[4,5]$. Among them, the three major players are the GA receptors, the DELLA repressor proteins, and the F-box proteins that control the stability of DELLA proteins. Ueguchi-Tanaka et al. [6] demonstrated that GID1 is a soluble GA receptor in rice (Oryza sativa). Discovery of the molecular identity of the endogenous plant GA-opposable growth-inhibitory factor resulted from molecular cloning of the genes encoding what are now known as the DELLA proteins.

The Arabidopsis gai mutation confers dominant, GAinsensitive dwarfism $[7,8]$. An insertional mutagenesis

\section{Biomed Central}


approach has facilitated the molecular cloning of gai via isolation of a $D s$ transposon-inactivated allele [9]. The gai open reading frame carries a small in-frame deletion mutation and thus encodes an altered product, a mutant gai protein that lacks a 17-amino-acid segment, now known as the DELLA domain, named after its first five amino acids. Molecular genetic analysis of GA-insensitive dwarf mutants has also identified an F-box protein (SLY1) that is part of a DELLA-interacting E3 ubiquitin ligase that interacts with a C-terminal region of the DELLA protein [10-12] and targets DELLAs for breakdown by the proteasome. DELLA proteins are thought to repress plant growth, and gibberellins promote growth by overcoming the repressive effects of these proteins. The Arabidopsis gai-1 mutant has a 51-bp deletion that encodes part of the conserved DELLA domain. As mentioned above, the $\Delta$ DELLA form of GAI acts as a gain-of-function mutant that can inhibit some components of the GA signaling pathway [9]. Expression of Arabidopsis gai in rice yields a dwarf phenotype, suggesting that GAI is sufficiently conserved between plant families to allow it to function [13].

Haywood et al. [14] have reported the long-distance delivery of RNA for the Arabidopsis $\triangle D E L L A$-gai (Atgai) genes. In grafting experiments, they demonstrated that the gai transcript specifically entered functional sieve elements and induced a highly reproducible change of leaf phenotype in tomato when Atgai mRNA was transported into the tomato shoot apex [14]. Long-distance transport of the GAI transcript in woody plants (Malus and Pyrus) has also been demonstrated [15,16]. Ham et al. [17] reported that the polypyrimidine tract binding motif within the GAI mRNA is involved in the formation of a mobile ribonucleoprotein complex, and proposed the presence of motifs that are necessary and sufficient for long-distance trafficking of the GAI transcript. Furthermore, Huang and $\mathrm{Yu}$ [18] reported that the trafficking of GAI RNA is mediated by specific RNA motifs existing among coding sequences and the 3 '-untranslated regions.

Experiments using a grafting system have provided longdistance transport of several transcripts across a graft union, such as CmPP16 (encoding a 16-kDa Cucurbita maxima phloem protein) [19], CmNACP (Cucurbita maxima non-cell-autonomous protein) [20], PFP (pyrophosphate-dependent phosphofructokinase) -LeT6 [21,22], StBEL5 (Solanum tuberosum BEL1-like transcription factor) [23,24] and AUX/IAA14 [25,26]. However, no details of the molecular mechanism involved, especially the physiological function of the GAI mRNA transport system, have been clarified. In the present study, we characterized GAI mRNA transport through phloem using Atgai transgenic tobacco as the experimental material. The results proved that a WT scion on Atgai rootstock contained the Atgai protein and that its growth reflected attenuation of the expression of many GA response genes.

\section{Results}

Atgai transgenic tobacco exhibits dwarfism and lower sensitive to $\mathrm{GA}_{3}$

Transgenic plants over expressing Atgai and showing a dwarf phenotype have been demonstrated in tomato, tobacco and apple $[16,27,28]$. Since Atgai mRNA has been shown to be transportable through phloem, a T-DNA construct harboring a construct expressing Atgai $(\mathrm{CgT})$ driven by a companion cell-specific promoter (Figure 1) was integrated into $N$. benthamiana by Agrobacterium transformation. $C g T$ transgenic tobacco plants clearly exhibited a semi-dwarf phenotype and did not show accelerated growth from 7 days after planting, as was the case for WT plants. Even after GA treatment, the $C g T$ plants showed only a small increase in stature, being about one fourth that of WT plants (Figure 2).

\section{CgT rootstock affects WT scion growth}

To determine whether $C g T$ rootstock affects growth of a WT scion as a result of Atgai mRNA transport, grafts consisting of a WT scion and a $C g T$ stock (WT/CgT) and a CgT scion and a WT stock $(C g T / \mathrm{WT})$ were treated with $\mathrm{GA}_{3}$ (Figure 3). Self-grafted WT and $C g T$ plants (WT/WT and $C g T / C g T$ ) were also prepared. These grafted plants were grown on soil in pots and sprayed with water with or without $\mathrm{GA}_{3}$. The GA-treated WT/ WT and WT/CgT combinations showed a typical GA response phenotype: rapid elongation, a slender growth form, and yellowish leaves, but the response of the $\mathrm{CgT} /$ $\mathrm{CgT}$ combination was not so obvious (Figure 4). Moreover, the shoot stature of $\mathrm{WT} / \mathrm{CgT}$ was approximately half that of WT/WT, indicating that the WT scion grafted on $\mathrm{CgT}$ was less sensitive to $\mathrm{GA}_{3}$.

Using hydroponic culture, as shown in Figure 3, the growth rates of the graft shoot and root were measured precisely. The $C g T$ rootstock reduced the stature of the

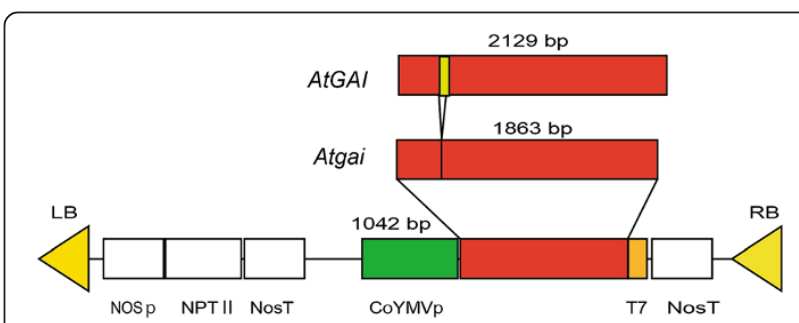

Figure 1 Vector structure of CgT. CoYMVp; Commelina yellow mottle virus promoter; Atgai: Arabidopsis thaliana gai gene (a gain-of-function DELLA allele of AtGAI), T7; T7-epitope tag (an 11-amino-acid peptide encoded in the leader sequence of T7 bacteriophage gene 10), Np; Nos promoter, NPT II; A gene encoding kanamycin resistance (primarily neomycin phosphotransferase II), Nt; Nos terminator. 


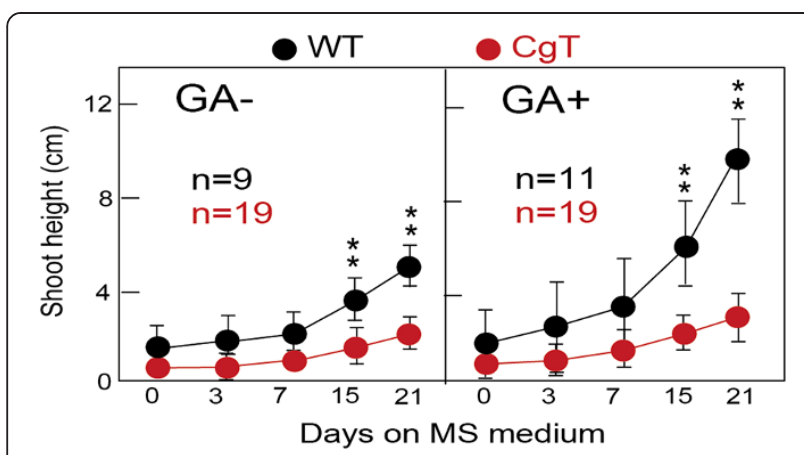

Figure 2 Growth rates of $C g T$ and WT. CgT and WT tobacco were grown on MS medium in a bottle for three weeks. GA+ indicates the results obtained from plants grown on MS agar containing $\mathrm{GA}_{3}$. ${ }^{* *} \mathrm{P}<0.01$ (Student's $t$ test) for comparisons between CgT and WT.

WT scion, and the $C g T$ scion also reduced the length of the WT rootstock (Additional file 1). To observe the effect of $C g T$ on the grafted partner's mass, shoot and root fresh weights for four graft combinations were measured. The combination showing the highest mass for both the shoot and root was WT/WT, followed in order by WT/CgT, $C g T / \mathrm{WT}$, and $C g T / C g T$ (Figure 5). Histograms were constructed (Additional file 2) using these individual graft data. Although variability among the growth rates of individual grafts was evident, $C g T$ obviously reduced the growth rate of the grafted WT scion.

\section{Transport of Atgai mRNA through the graft union}

Any effect of $C g T$ rootstock on the WT graft would be caused by long-distance transport of Atgai mRNA through the graft union. To confirm this, RT-PCR was used to detect the mutant mRNA in the grafted material. Thirteen WT scions out of $63 \mathrm{WT} / C g T$ paired combinations showed amplification of a clear Atgai product of the predicted size, 347 bp (Additional file 3), indicating that longdistance transport of Atgai transcripts had occurred in some grafts, whereas no product was detected in $21 \mathrm{WT} /$ WT paired combinations. To quantify the transported Atgai mRNAs, we chose six WT/CgT scions at random and tried to detect the Atgai transcript in them using qRT-PCR (Figure 6). Three of the six WT scion samples clearly showed an amplified product; the others showed a very small amount of the amplified product that was detectable only by qRT-PCR. Sequencing of the amplified fragments confirmed that they were derived from Atgai, thus demonstrating that transport of the mRNA through the graft unions varied among individuals.

\section{Detection of Atgai-T7 protein in the scion of the WT/CgT combination}

Since Atgai mRNA was shown to be transported, we tested whether the mRNA was also present in WT scions grafted onto $\triangle$-DELLA-Atgai rootstock. The scions of WT/WT and $C g T / C g T$ homogeneous grafts were used as negative and positive controls $(n>5)$, respectively. Leaves from five scions of the WT/CgT combination, in which Atgai mRNA had been positively detected, were harvested carefully and analyzed by Western blotting using a T7-tag antibody (Figure 7). A clear band closely matching the predicted size $(57 \mathrm{kDa})$ of Atgai-T7 was detected in the WT scion grafted on the $C g T$ stock. Although it was considered that Atgai mRNA was transportable from the $\mathrm{CgT}$ stock to the WT scion and then translated into protein in the scion tissue, the movement of the protein itself from the stock to the scion is also a possibility.

\section{Attenuation of the GA response of the WT scion on CgT stock revealed by microarray}

To investigate in detail the GA response of the scion on $C g T$ stock, microarray analyses were performed using three mRNA samples obtained from the scions of the $\mathrm{WT} / \operatorname{Cg} T(\mathrm{GA}), \mathrm{WT} / \mathrm{WT}(\mathrm{GA})$, and WT/WT combinations (GA in parenthesis indicates $\mathrm{GA}_{3}$-treated plants, as shown in Figure 3), and differences in the resulting changes of gene expression among the "WT/WT (GA) vs "WT/WT and *WT/CgT (GA) vs *WT/WT combinations ("WT indicates samples used for RNA extraction) were compared. Out of 18,588 unique genes, genes exhibiting changes in expression of over 100 and below 0.01 in at least one of both combinations were removed. The remaining 18,418 genes were selected, and their changes in expression were plotted on an X-Y scattergram, where the $\mathrm{X}$ axis $={ }^{*} \mathrm{WT} /$ $\mathrm{WT}(\mathrm{GA})$ vs "WT/WT and the Y-axis = "WT/CgT (GA) vs

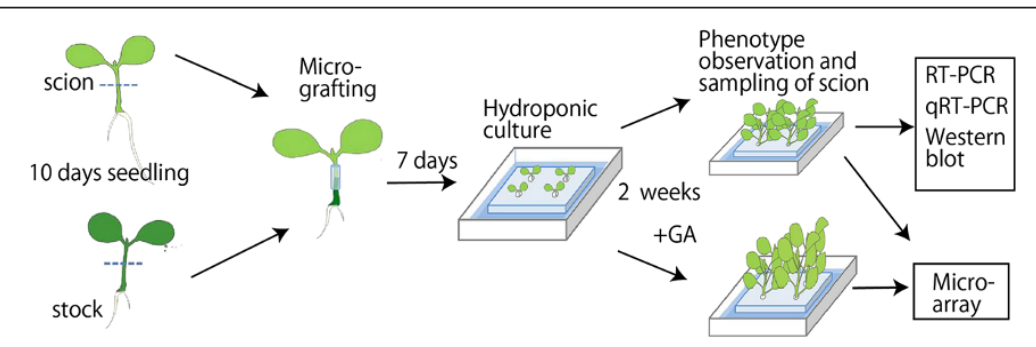

Figure 3 Illustration of the experimental procedure using grafted tobacco plants. Respective methodological details appear in each section of the body text. 


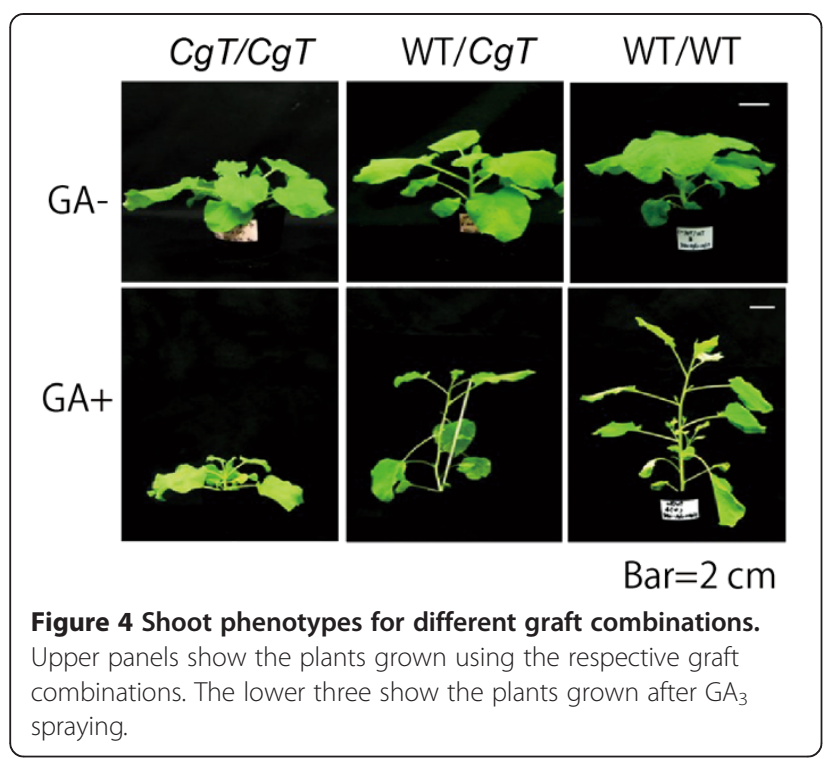

*WT/WT (Figure 8). The regression line from all plots approached the $\mathrm{X}$-axis, with a slope of 0.775 , indicating that the GA response of genes in the ${ }^{*} \mathrm{WT} / \mathrm{CgT}$ (GA) combination was weaker than that of genes in the "WT/ WT (GA) combination. In order to confirm this, the data from all 18,418 genes were separated into 9 classes

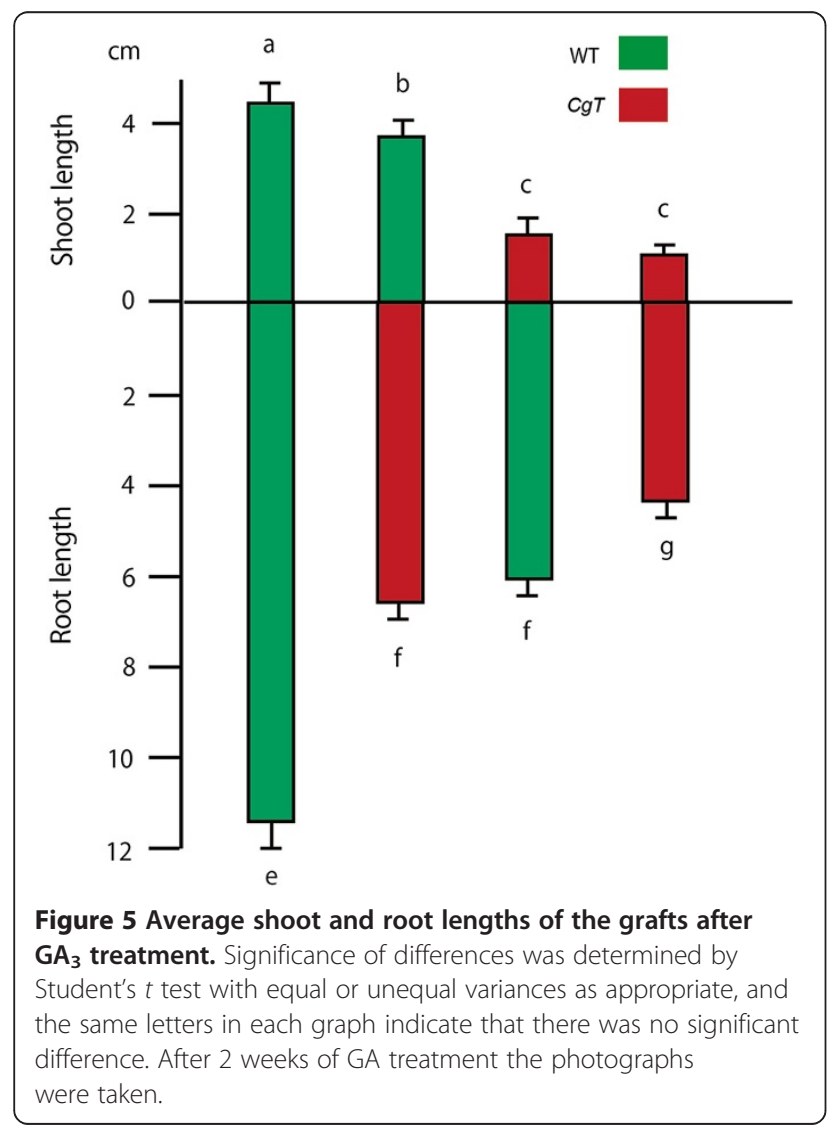

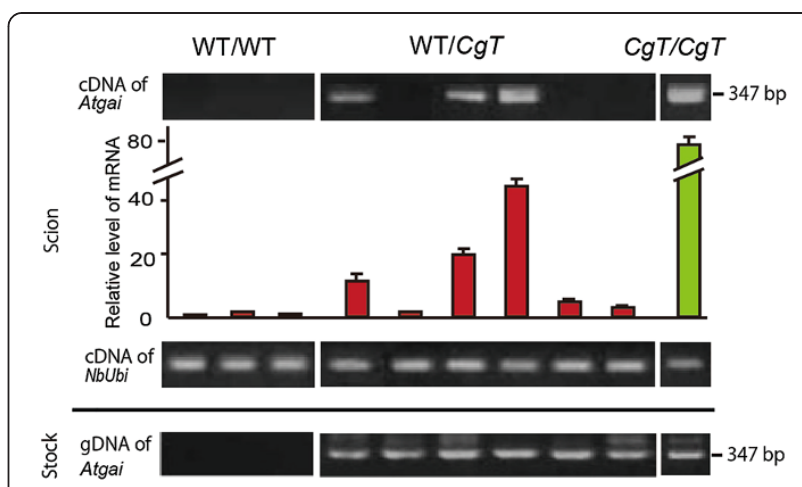

Figure 6 Detection of Atgai mRNA in WT scions on CgT rootstock. At 21 days after grafts had been established, three, six and one were randomly harvested from 21 WT/WT, 63 WT/CgT, and $7 \mathrm{CgT} / \mathrm{CgT}$, respectively. The scion leaves were used for RT-PCR and qRT-PCR analyses of Atgai mRNA. NbUbi (ubiquitin of N. benthamiana) was amplified as a control. The stock was used for PCR of the Atgai transgene.

according to the degree of the change in expression (Table 1), and the distributions of the numbers of genes were compared between *WT/WT(GA) vs "WT/WT and "WT/CgT (GA) vs "WT/WT. The change in expression in the former case showed that 2,115 genes $(\geq 2)$ and 1,754 genes $(\leq 0.5)$ exhibited enhanced and reduced expression, respectively. On the other hand, the change in expression in the latter case showed that 1,827 and 1,494 genes exhibited enhanced and reduced expression, respectively. In total, 548 genes (3869-3321) showed a class $\mathrm{E}$ change in expression $(\leq 0.5 \sim 22)$. These results clearly demonstrated that the WT scions on $C g T$ stocks had fewer genes whose expression was altered in response to GA treatment, resulting that the $\mathrm{CgT}$ rootstock attenuated the GA response in the WT scion.

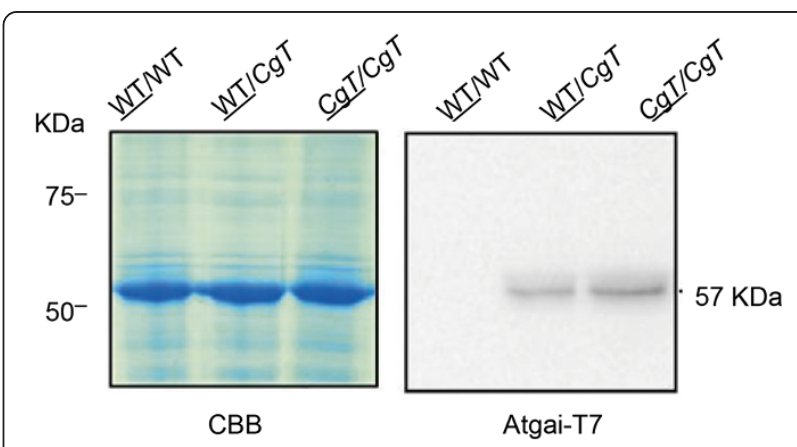

Figure 7 Western blotting for detection of Atgai-T7 protein in the WT scion grafted onto CgT stock. Using a T7-tag antibody, Atgai-T7 protein was identified in a bulked WT scion sample from five grafts in which Atgai mRNA had been positively detected (Figure 5). Bulked samples of WT and CgT homogeneous grafts were used as negative and positive controls, respectively. Each lane was loaded with $25 \mu \mathrm{g}$ protein. 


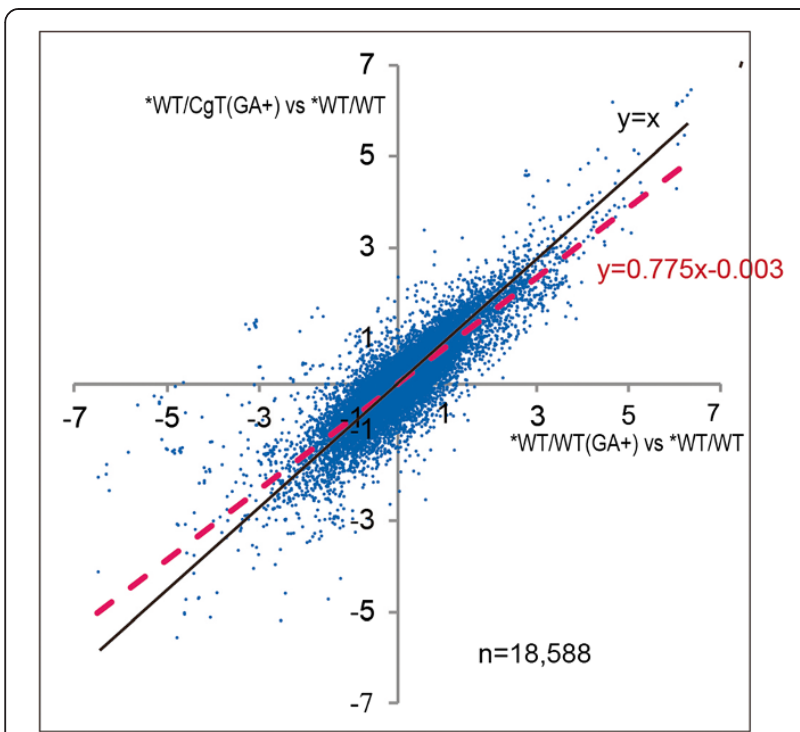

Figure 8 Relationships among degrees of change in expression of 18,418 genes for different graft combinations. The $X$ and $Y$ axes represent *WT/WT (GA+) vs *WT/WT and *WT/CgT (GA+) vs *WT/NT, respectively. ${ }^{*} W T$ indicates the scions used for microarray analysis. The numerical values were $\log 2$-transformed and the degrees of change were plotted on the respective axes. The calculated regression line is shown as a red broken line.

\section{Atgai apple rootstock reduces the stature of the scion cultivar}

Malus prunifolia is a non-dwarf-type apple rootstock used predominantly in Japan. We attempted to transform M. prunifolia by introducing the Atgai gene by the Agrobacterium method. Several putative transgenic lines were obtained in two transformation experiments. Through propagation of the shoots on a medium containing the selection marker, only one line (Atgai-26) was confirmed as transgenic by Southern blot hybridization (Additional file 4). The limitations of obtaining a single

Table 1 Numbers of genes exhibiting different degrees of GA response

\begin{tabular}{ccc}
\hline $\begin{array}{c}\text { Class (degree } \\
\text { of change) }\end{array}$ & \multicolumn{2}{c}{ Numbers of genes } \\
\cline { 2 - 3 }${ }^{* W T / W T(G A) ~ t o ~ * W T / W T ~}$ & $*$ WT/CgT(GA) to *WT/WT \\
\hline$A(<20 \sim \leq 100)$ & 35 & 24 \\
$\mathrm{~B}(<10 \sim \leq 20)$ & 81 & 45 \\
$\mathrm{C}(<5 \sim \leq 10)$ & 331 & 182 \\
$\mathrm{D}(<2 \sim \leq 5)$ & 1668 & 1576 \\
$\mathrm{E}(<0.5 \sim \leq 2)$ & 14549 & 15097 \\
$\mathrm{~F}(>0.5 \sim \geq 0.4)$ & 786 & 663 \\
$\mathrm{G}(>0.4 \sim \geq 0.3)$ & 493 & 412 \\
$\mathrm{H}(>0.3 \sim \geq 0.2)$ & 248 & 262 \\
$\mathrm{I}(>0.2 \sim \geq 0.01)$ & 227 & 157 \\
\hline
\end{tabular}

transgenic line was likely due to the low transformation efficiency in Malus species and the effect of the Atgai introduced, suppression of GA signaling. The Atgai-26 M. prunifolia exhibited a semi-dwarf phenotype with reduced sensitivity to GA treatment, as is the case for $\mathrm{Cg} T$ tobacco (Additional file 5). Moreover, the grafts between Atgai-26 stock and scions of the apple variety 'Orin' showed a clearly reduced shoot stature (Figure 9). Although these results are based on a single transgenic apple line, the data are consistent with the results in tobacco.

\section{Discussion}

Lack of the DELLA domain of GAI results in constitutive activation of a mutant growth inhibitor whose genetically dominant action can no longer be opposed by GA. Since gai is a semi-dominant and gain-of-function mutation [8], integration of gai into WT results in a semi-dwarf phenotype, and this has contributed to the Green Revolution [29]. The stature of several crops, including rice [13], Chrysanthemum [30], tobacco [27], and apple [28], has been reduced by transformation with $\triangle D E L L A-G A I$ (gai), as is the case for the Arabidopsis gai-1 allele. In all cases, $\triangle D E L L A-G A I$ (gai) was expressed under the control of CaMV 35 S (Cauliflower Mosaic Virus promoter 35S).

On the other hand, GAI mRNA is able to move through phloem, and is considered to function at the site(s) to which it has been transported $[14,18]$. As plasmodesmata connect the functional enucleate sieve elements of the phloem to their neighboring companion cells [31], this pathway is considered to allow the selective entry of

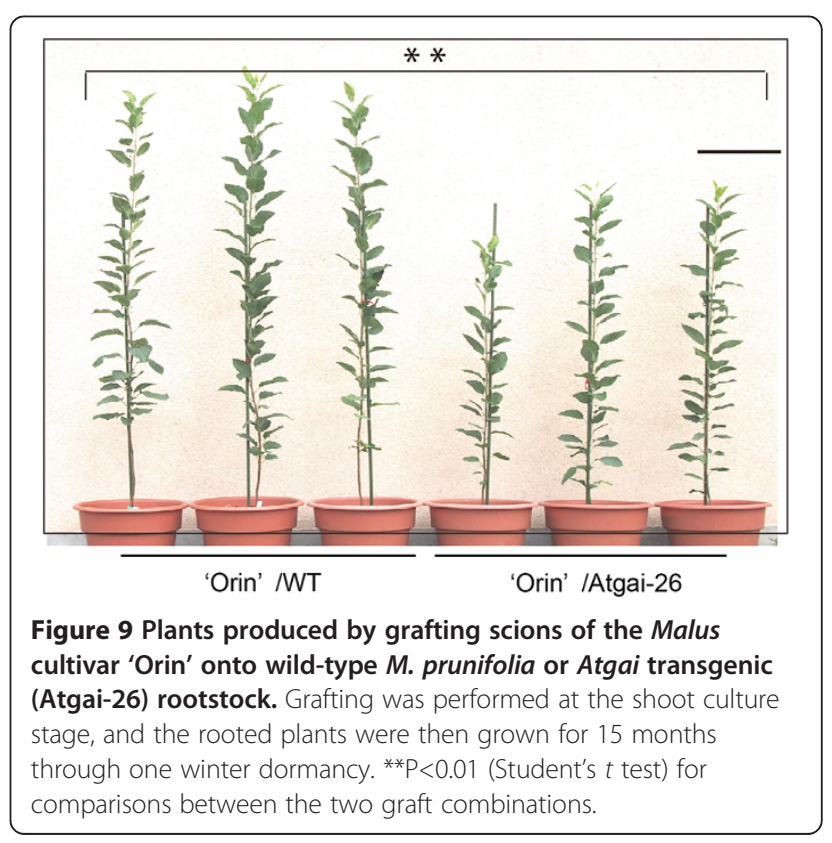


information macromolecules into the phloem translocation stream. In this study, the Atgai transgene was delivered via the promoter of a plant virus, CoYMV, which is expressed strongly only in companion cells [32]. Intriguingly, the $\mathrm{Cg} T$ transgenic tobacco plants also exhibited semi-dwarf phenotypes, as was the case when the $35 \mathrm{~S}$ promoter was used, indicating that expression of Atgai only in companion cells can induce a definite dwarf phenotype. Therefore, it is suggested that the GAI transcript in companion cells acts non-cell-autonomously to regulate the growth of plants. Furthermore, the less sensitive GA response of the WT scion on $C g T$ rootstock strongly indicated the non-cell-autonomous effect of the $G A I$ transcript. In higher plants the system of GAI mRNA transport through the phloem might function to integrate growth modalities among plant organs [14]. In our experiments, not only the integrated Atgai but also the extant $N$. benthamiana GAI were considered to be transported by the same molecular mechanism. Detailed analysis of the transport of both gene transcripts via the graft union would be expected to clarify the physiological role of GAI mRNA long-distance movement.

Approximately one-fourth of the grafts we examined did not show the RT-PCR product derived from the gai mRNA transported from the stock. Long-distance transport of RNA in sieve tubes appears to be mediated by RNA-binding proteins. Ham et al. [17] identified RNAbinding proteins involved in mRNA transport, and proposed a model in which a ribonucleoprotein complex moves in the phloem. It is clear that RNA also binds to chaperone proteins for stability and delivery to target tissues [18]. As a matter of course, such large complexes must pass through the graft union, where vascular bundles are developed in the callus (Additional file 6). De novo passage through the sieve tube tends to be unorthodox, showing features such as a winding path, thus disrupting the passage of large ribonucleoprotein complexes, and in extreme cases such complexes would become clogged. Since the conductance of a vessel is proportional to the fourth power of the vessel radius (Hagen-Poiseulle law), a slightly reduced diameter would pose an obstacle to passage. On the other hand, grafting of many horticultural crops is a well-developed technology, and this phenomenon in such plants might be less problematic, suggesting that they can establish near-complete connection of the sieve tube at the graft union as the growth progressed.

No other report has identified the translated protein derived from the transported gai mRNA in grafting experiments. In the WT scion on the CgT stock, the gai protein fused with the T7-tag peptide was clearly detectable. Its amount was considered to be approximately one-third of that in the CgT stock, suggesting effective translation of the gai mRNA in the scion. However, there is a possibility that the protein might have been translated in companion cells and then moved through the graft union. For clarification of this issue, a highaccuracy experiment to detect the GAI protein in sieve elements would be necessary.

Our present microarray experiment was also the first of its kind to investigate the long-distant distance transport of mRNA in grafted plants. The overall results clearly revealed that the WT scions on $C g T$ stocks had fewer genes whose expression was altered in response to GA treatment than in the WT scions on WT stocks. It is known that GA has pronounced effects on overall reproductive growth from flowering to fruiting [33]. Therefore, although we succeeded in growing a dwarf apple tree using the Atgai rootstock, the effect of this manipulation on subsequent fruit development will require careful investigation. However, semi-dwarf cultivation of many crops might be feasible using Atgai-expressing rootstock. Furthermore, the application of not only GAI but also other phloem-transportable mRNAs [21,23,26] might become possible by means of grafting. Finally, the present results imply that a non-genetically modified scion is capable of improvement by a genetically modified rootstock, and consequently, the fruits of the plant would not contain the inserted DNA sequence. Grafting using gene-modified rootstock is expected to become a focus of interest as an innovative approach to agriculture [34].

\section{Conclusions}

This study has demonstrated for the first time that transgenic stock expressing a $\triangle D E L L A-g a i$ gene by the companion cells specific-promoter is able to transfer the gaimRNA to a wild-type scion. Furthermore, this study provides the first evidence that the translated product of the gai mRNA is present in the scion. In addition, microarray data clearly indicated that many GA-responsive genes in the wild-type scion on $\triangle$ DELLA-gai stock show attenuated responses.

\section{Methods}

\section{Plant materials and growth conditions}

Nicotiana benthamiana was grown on MS [35] agar (Wako Pure Chemical Industries Ltd., Osaka, Japan) plates in a Petri dish or a glass bottle. Grafted tobacco plants were cultivated on soil in a pod. Hydroponic culture was also performed using a styrofoam plate floating on hydroponic solution (Otsuka House Nos. 1 and 2, Otsuka Chemical Co., Osaka, Japan). The cultures were incubated at $24^{\circ} \mathrm{C}$ with a $16: 8$-h photoperiod under $100 \mu \mathrm{mol} \mathrm{m} \mathrm{m}^{-2} \mathrm{~s}^{-1}$ provided by cool-white fluorescent tubes. Wild apple rootstock (Malus prunifolia Borkh. var. ringo Asami Mo 84-A) was used for transformation. The grafts of Malus plants were transplanted on a pod and grown in a greenhouse [36]. 


\section{Construction of the binary vector}

Arabidopsis seed (gai-1, CS63) was provided by the Arabidopsis Biological Resource Center (Ohio State University). The CS63 plantlets were used to extract the RNA fraction to obtain the full cDNA of the Atgai gene harboring a 51-bp deletion from the region encoding the con-

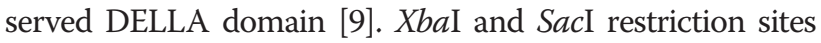
were added to the 5 ' - and 3 '- sites of the Atgai fragment by PCR using the primers AtgaiXba and AtgaiSac (Additional file 7). The GUS fragment was deleted from $p B I 121$ with $\mathrm{XbaI}$ and SacI [37], and then replaced with the new Atgai fragment. The $35 \mathrm{~S}$ promoter was deleted from the vector by SalI and double-digested by with SpeI and XbaI. The Commelina yellow mottle virus promoter $(\mathrm{CoYMVp})$ of pCOI [38] (from Prof. Neil Olszewski, University of Minnesota, St. Paul, MN, USA), which is expressed specifically in companion cells [39], was amplified by the primers CoYMVproFPSal and CoYMVproRPSpe, and then used to replaced the $35 \mathrm{~S}$ promoter sequence with the SalI and SpeI sites (Additional file 7). A T7-epitope tag sequence (MASMTGGQQMG, Invitrogen, USA) was inserted into the 3' - site of CoYMVp: Atgai by PCR. The forward primer was CoYMVproFl, and the primer T7tag R including the T7-epitope tag sequence was used as the reverse primer. The new vector was sequenced to ensure correct insertion. The CoYMVp:Atgai-T7 (CgT) fused gene was cloned in $p B 1121$ (Figure 1) carrying the nos-kanamycin resistance cassette. Transgenic lines were identified by PCR with the primers CoYMproFP1 and AtgaiR1 to detect the $\triangle$-DELLA -gai. kihyufg (Additional file 7).

\section{Grafting experiment}

Micrografting was performed according to the method described by Bai et al. [40]. Briefly, as shown in Figure 2, plantlets 10 days after germination were grafted under a stereomicroscope on a clean bench. The plant was cut horizontally approximately $3 \mathrm{~mm}$ below the cotyledon. Then the scion (tissue with the cotyledon) and rootstock (tissue at the bottom with root) were fastened together with a silicone tube $(\phi 0.4 \mathrm{~mm} \times 0.1 \mathrm{~mm}, 3 \mathrm{~mm}$ length; TechJam, Osaka, Japan). The grafted plants were each propped against an agar block on MS agar medium. At 7 days after grafting, the silicone tube was cut off. The grafts were then cultivated in soil or using a standard nutrient solution (Otsuka House Nos. 1 and 2, Otsuka Chemical Co., Osaka, Japan) until phenotype observation or sampling. In the case of Malus plants, cleft grafting between subcultured shoots was performed.

\section{$\mathrm{GA}_{3}$ treatment}

Grafted plants that had been grown for 7 days in a Petri dish were transferred to pots with nursery soil. After 1 week, they were sprayed with $0.1 \mathrm{mM} \mathrm{GA} \mathrm{G}_{3}$ solution (Nakarai Tesque, Inc. Kyoto, Japan) containing 0.02\% Tween 20 once every two days for three weeks. For RTPCR, protein extraction, microarray and seedling stature measurement, plants were cultured hydroponically for 9 days, then sprayed with $0.1 \mathrm{mM} \mathrm{GA}_{3}$ solution.

\section{RNA extraction, RT-PCR and qRT-PCR analysis}

Total RNA was extracted from leaves with TRIzol reagent (Invitrogen, Tokyo, Japan), and genomic DNA was eliminated with a TURBO DNA-free Kit (Ambion Inc., Austin, USA). Reverse-transcribed cDNAs were prepared using a SuperScript ${ }^{\circ}$ VILO $^{\text {max }}$ cDNA Synthesis Kit (Invitrogen, USA). The cDNA corresponding to $50 \mathrm{ng}$ of total RNA was used in 10- $\mu$ l reactions with an S1000 Thermal Cycler (Bio-Rad, USA). To amplify Atgai mRNA in the WT scion, primers (AtgaiF2 and AtgaiR2) and the nested primers (AtgaiF3 and AtgaiR3) were prepared. The amplification condition were as follows: initial denaturing at $94^{\circ} \mathrm{C}$ for 4 min, 25 cycles at $94^{\circ} \mathrm{C}$ for $30 \mathrm{~s}, 58^{\circ} \mathrm{C}$ for $30 \mathrm{~s}$, and $72^{\circ} \mathrm{C}$ for $1 \mathrm{~min}$; and extension at $72^{\circ} \mathrm{C}$ for $3 \mathrm{~min}$. For the nested PCR, $1 \mu \mathrm{l}$ of the first PCR product was used as the template and subjected to 30 cycles. For qRT-PCR, $1 \mu \mathrm{l}$ of the cDNA corresponding to $50 \mathrm{ng}$ of total RNA was used in 20- $\mu$ l reactions with iQ SYBR Green Supermix (Bio-Rad, USA). Triplicate reactions for each sample were amplified along with non-template controls on a Chromo 4 realtime PCR detector (Bio-Rad, USA). NbUbi (Accession No.: AY912494) was used to normalize the expression levels of Atgai. Primers (Atgai QF/Atgai QR and Ubi QF/ Ubi QR) specific to the Atgai and NbUbi genes were used in this experiment (Additional file 7).

\section{Protein extraction and immunoblotting}

About $3.0 \mathrm{~g}$ of scion shoot tissue $(\mathrm{n}=5)$ was sampled after mRNA transport had been positive detected, and then ground in liquid nitrogen using a pre-cooled mortar and pestle. Protein was extracted according to the method described previously [41]. The concentration of protein was measured by DC Protein Assay (Bio-Rad, USA). Total proteins $(25 \mu \mathrm{g})$ were mixed with a SDS loading buffer, and heated at $95^{\circ} \mathrm{C}$ for 5 minutes for denaturation, then fractionated by SDS-PAGE (sodium dodecyl sulfate polyacrylamide gel electrophoresis). SDSPAGE was performed in $12.5 \%$ polyacrylamide gels using Bio-Rad Mini-PROTEAN 4 equipment at 200V for $1 \mathrm{~h}$. Proteins were transferred to Immun-Blot ${ }^{\mathrm{Tm}}$ PVDF membranes (Bio-Rad, USA). Then, each membrane was blocked with BSA (bovine serum albumin, Sigma, Germany) at room temperature for $1 \mathrm{~h}$ (in the blocking buffer, BSA was dissolved in $1 \times$ TBS- $0.1 \%$ Tween to a final concentration $0.02 \mathrm{~g} / \mathrm{mL}$ ). For analysis of the immunoblots, the membranes were incubated with $0.1 \mu \mathrm{g} / \mathrm{mL}$ anti-T7-peptide monoclonal antibody (Novagen, USA) at $4^{\circ} \mathrm{C}$ overnight, 
and then washed 4 times for $1 \mathrm{~h}$ at room temperature. The membranes were then incubated with a 2,000-fold dilution of anti-mouse IgG, Goat Poly HRP (Cosmo Bio Co., Ltd., Tokyo, Japan) for $1 \mathrm{~h}$, and washed 3 times for $1 \mathrm{~h}$ at room temperature. The signals were detected using an Amersham ECL Plus Western Blot Detection System (GE Healthcare, UK). A duplicate gel was run at the same time and then stained with Coomassie Brilliant Blue R250 as a loading control.

\section{Microarray analysis}

Five WT scions in which the Atgai mRNA transported from the $C g T$ stock had been detected by RT-PCR were combined, and total RNA was prepared from the sample. Five scions for the WT/WT combination with and without $\mathrm{GA}_{3}$ treatment were also combined and used as samples for RNA extraction. The purification, labeling of cRNA, hybridization to $44 \mathrm{~K}$ Tobacco DNA microarray (Agilent Techologies), signal scanning, and processing were performed by Hokkaido System Science Co., Ltd. (Japan) with a Low Input Quick Amp Labeling Kit using an Agilent Technologies Microarray Scanner (Agilent Techologies, USA). A total of 18,588 unique genes that passed the stringent quality control were used for inspection.

\section{Additional files}

Additional file 1: Shoot and root growth rates in respective grafts after $\mathrm{GA}_{3}$ treatment.

Additional file 2: Histograms of shoot and root lengths of grafts between different graft combinations. The arrowhead indicates the average of the population.

Additional file 3: RT-PCR detection of CgT transcript of grafts between different graft combinations.

Additional file 4: Southern blot result of Atgai-26 with Atgai probe. $15 \mu \mathrm{g}$ of gDNAs were loaded in each lane. Lane 1: digested by EcoRV. Lane 2: digested by HindIII. +: plasmid as positive control.

Additional file 5: Stature of Atgai-26 and Wild Type M. prunifolia. At four weeks after spraying the water with or without $\mathrm{GA}_{3}(0.1 \mathrm{mM})$, the shoot statures were photographed.

Additional file 6: Turbulent structure of phloem line at graft junction of $\boldsymbol{N}$. benthamiana. The wild type plant were grafted on CoYMV:GUS transgenic plant by micro-grafting technique. After 2 weeks, the phloem conflation was observed by GUS staining.

Additional file 7: Primers sequences used in this study.

\section{Abbreviations}

CgT: CoYMVp:Atgai-T7; GA: Gibberellic acid; GAl: Gibberellic acid insensitive; MS: Murashige and Skoog medium; T7: T7 (bacteriophage) -epitope tag CoYMVp: Commelina yellow mottle virus.

\section{Competing interests}

The authors declare that they have no competing interests.

\section{Authors' contribution}

$\mathrm{HX}$ and $\mathrm{TH}$ designed the experiments; HX and RI conducted most of research and analyzed the data together with $\mathrm{TL}$ and $\mathrm{TH}$; all authors contributed to the writing of the manuscript. All authors read and approved the final manuscript.

\section{Acknowledgements}

This research was funded by the Adaptable and Seamless Technology Transfer Program through target-derived R\&D of the Japan Science and Technology Agency, and by a Grant for Institutional Research at Hirosaki University.

\section{Author details}

${ }^{1}$ Faculty of Agriculture and Life Science, Hirosaki University, Hirosaki 036-8561, Japan. ${ }^{2}$ The United Graduate School of Agricultural Sciences, Iwate University, Morioka 020-8550, Japan. ${ }^{3}$ Laboratory of Fruit Cell and Molecular Breeding, China Agriculture University, Beijing 100193, China. ${ }^{4}$ Present address: Research Institute of Forestry, Chinese Academy of Forestry, Beijing 100091, China.

Received: 3 November 2012 Accepted: 10 October 2013

Published: 21 October 2013

\section{References}

1. Richards DE, King KE, Ait AT, Harberd NP: How gibberellin regulates plant growth and development: a molecular genetic analysis of gibberellin signaling. Annu Rev Plant Physiol Plant Mol Biol 2001, 52:67-88.

2. Yamaguchi S: Gibberellin metabolism and its regulation. Annu Rev Plant Biol 2008, 59:225-251.

3. Sun TP: Gibberellin-GID1-DELLA: a pivotal regulatory module for plant growth and development. Plant Physiol 2010, 154:567-570

4. Sun TP, Gubler F: Molecular mechanism of gibberellin signaling in plants. Annu Rev Plant Biol 2004, 55:197-223.

5. Hartweck LM, Olszewski NE: Rice GIBBERELLIN INSENSITIVE DWARF1 is a gibberellin receptor that illuminates and raises questions about GA signaling. Plant Cell 2006, 18:278-282

6. Ueguchi-Tanaka M, Ashikari M, Nakajima M, Itoh H, Katoh E, Kobayashi M, Chow TY, Hsing Yl, Kitano H, Yamaguchi I, Matsuoka M: GIBBERELLIN INSENSITIVE DWARF1 encodes a soluble receptor for gibberellin. Nature 2005, 437:693-698

7. Koorneef M, Elgersma A, Hanhart CJ, van Loenen-Martinet EP, van Rijn L, Zeevaart JAD: A gibberellins insensitive mutant of Arabidopsis. Physiol Plant 1985, 65:33-39.

8. Peng J, Harberd NP: Derivative alleles of the Arabidopsis gibberellininsensitive (gai) mutation confer a wildtype phenotype. Plant Cell 1993, 5:351-360.

9. Peng J, Carol P, Richards DE, King KE, Cowling RJ, Murphy GP, Harberd NP: The Arabidopsis GAl gene defines a signaling pathway that negatively regulates gibberellin responses. Genes Dev 1997, 11:3194-3205.

10. McGinnis KM, Thomas SG, Soule JD, Strader LC, Zale JM, Sun TP, Steber CM: The Arabidopsis SLEEPY1 (SLY1) gene encodes a putative F-box subunit of an SCF E3 ubiquitin ligase. Plant Cell 2003, 15:1120-1130.

11. Dill A, Thomas SG, Hu J, Steber CM, Sun TP: The Arabidopsis F-box protein SLEEPY1 targets gibberellin signaling repressors for gibberellin-induced degradation. Plant Cell 2004, 16:1392-1405.

12. Fu XD, Richards DE, Fleck B, Xie D, Burton N, Harberd NP: The Arabidopsis mutant sleepy $1^{\text {gar2-1 }}$ protein promotes plant growth by increasing the affinity of the $\mathrm{SCF}^{\mathrm{SLY} 1} \mathrm{E} 3$ ubiquitin ligase for DELLA protein substrates. Plant Cell 2004, 16:1406-1418.

13. Fu XD, Sudhakar D, Peng JR, Richards DE, Christou P, Harberd NP: Expression of Arabidopsis $G A /$ in transgenic rice represses multiple gibberellin responses. Plant Cell 2001, 13:1791-1802.

14. Haywood V, Yu TS, Huang NC, Lucas WJ: Phloem long-distance trafficking of Gibberellic Acid-Insensitive RNA regulates leaf development. Plant J 2005, 42:49-68.

15. Xu H, Zhang W, Li M, Harada T, Han Z, Li T: Gibberellic Acid Insensitive mRNA transport in both directions between stock and scion in Malus. Tree Genet Genom 2010, 6:1013-1019.

16. Wang SS, Liu ZZ, Sun C, Shi QH, Yao YX, You CX, Hao YJ: Functional characterization of the apple MhGAl1 gene through ectopic expression and grafting experiments in tomatoes. J Plant Physiol 2012, 169:303-310.

17. Ham BK, Brandom JL, Xoconostle-Cazares B, Ringgold V, Lough TL, Lucas WJ: A polypyrimidine tract binding protein, pumpkin RBP50, forms the 
basis of a phloem-mobile ribonucleoprotein complex. Plant Cell 2009, 21:197-215.

18. Huang N, YU T: The sequences of Arabidopasis GA-INSENSITIVE RNA constiture the motifs that are necessary and sufficient for RNA long-distance trafficking. Plant J 2009, 59:921-929.

19. Xoconostle-Cázares B, Xiang Y, Ruiz-Medrano R, Wang HL, Monzer J, Yoo BC, McFarland KC, Franceschi VR, Lucas WJ: Plant paralog to viral movement protein that potentiates transport of mRNA into the phloem. Science 1999, 283:94-98.

20. Ruiz-Medrano R, Xoconostle-Cázares B, Lucas WJ: Phloem and long-distance transport of CMNACP mRNA, implications for supracellular regulation in plants. Development 1999, 126:4405-4419.

21. Kim M, Canio W, Kessler S, Shinha N: Developmental changes due to long-distance movement of a homeobox fusion transcript in tomato. Science 2001, 293:287-289.

22. Kudo $H$, Harada $T$ : A graft-transmissible RNA from tomato rootstock changes leaf morphology of potato scion. Hortic Sci 2007, 42:225-226.

23. Banerjee AK, Chatterjee M, Yu Y, Suh SG, Miller WA, Hannapel DJ: Dynamics of a mobile RNA of potato involved in a long-distance signaling pathway. Plant Cell 2006, 18:3443-3457.

24. Banerjee AK, Lin T, Hannapel DJ: Untranslated regions of a mobile transcript mediate RNA metabolism. Plant Physiol 2009, 151:1831-1843.

25. Omid A, Keilin T, Glass A, Leshkowitz D, Wolf S: Characterization of phloem-sap transcription profile in melon plants. J Exp Bot 2007, 58:3645-3656.

26. Kanehira A, Yamada K, Iwaya T, Tsuwamoto R, Kasai A, Nakazono M, Harada T: Apple phloem cells contain some mRNAs transported over long distances. Tree Genet Genom 2010, 6:635-642

27. Hynes LW, Peng JR, Richards DE, Harberd NP: Transgenic expression of the Arabidopsis DELLA proteins GAl and gai confers altered gibberellin response in tobacco. Transgenic Res 2003, 12:707-714.

28. Zhu LH, Li XY, Welander M: Overexpression of the Arabidopsis gai gene in apple significantly reduces plant size. Plant Cell Rep 2008, 27:289-296.

29. Peng J, Richards DE, Hartley NM, Murphy GP, Devos KM, Flintham JE, Beales J, Fish LJ, Worland AJ, Pelica F, Sudhakar D, Christou P, Snape JW, Gale MD, Harberd NP: 'Green revolution' genes encode mutant gibberellin response modulators. Nature 1999, 400:256-261.

30. Petty LM, Harberd NP, Carré IA, Thomas B, Jackson SD: Expression of the Arabidopsis gai gene under its own promoter causes a reduction in plant height in chrysanthemum by attenuation of the gibberellin response. Plant Sci 2003, 164:175-182.

31. Tyler L, Thomas GS, Hu J, Dill A, Alonso MJ, Ecker RJ, Sun T: DELLA proteins and Gibberellin-regulated seed germination and floral development in Arabidopsis. Plant Physiol 2004, 135:1008-1019.

32. Turgeon R: Phloem loading and plasmodesmata. Trends in Plant Sci 1996, 1:418-423.

33. Jackson DI: Gibberellin and the growth of peach and apricot fruits. Aust $J$ Biol Sci 1968, 21:209-215.

34. Lusser M, Parisi C, Plan D, Rodriguez-Grezo E: Deployment of new biotechnologies in plant breeding. Nature Biotech 2012, 30:231-239.

35. Murashige T, Skoog F: A revised medium for rapid growth and bioassays with tobacco tissue cultures. Physiol Plant 1962, 15:473-497.

36. Igarashi M, Ogasawara H, Hatsuyama Y, Saito A, Suzuki M: Introduction of ro/C into Marubakaidou [Malus prunifolia Borkh. var. ringo Asami Mo 84-A] apple rootstock via Agrobacterium tumefaciens. Plant Sci 2002, 163:463-473.

37. Chen PY, Wang CK, Soong SC, To KY: Complete sequence of the binary vector $\mathrm{pBI} 121$ and its application in cloning T-DNA insertion from transgenic plants. Mol Breeding 2003, 11:287-293.

38. Matsuda Y, Liang G, Zhu Y, Ma F, Nelson RS, Ding B: The commelina yellow mottle virus promoter drives companion-cell-specific gene expression in multiple organs of transgenic tobacco. Protoplasma 2002, 220:51-58.
39. Medberry SL, Lockhart BE, Olszewski NE: The Commelina Yellow Mottle Virus promoter is a strong promoter in vascular and reproductive tissues. Plant Cell 1992, 4:185-192.

40. Bai S, Kasai A, Yamada K, Li T, Harada T: A mobile signal transported over a long distance induces systemic transcriptional gene silencing in a grafted partner. J Exp Bot 2011, 62:4561-4570.

41. Wang W, Vignani R, Scali M, Cresti M: A universal and rapid protocol for protein extraction from recalcitrant plant tissues for proteomic analysis. Electrophoresis 2006, 27:2782-2786.

doi:10.1186/1471-2229-13-165

Cite this article as: Xu et al.: Long-distance transport of Gibberellic Acid Insensitive mRNA in Nicotiana benthamiana. BMC Plant Biology 2013 13:165

\section{Submit your next manuscript to BioMed Central and take full advantage of:}

- Convenient online submission

- Thorough peer review

- No space constraints or color figure charges

- Immediate publication on acceptance

- Inclusion in PubMed, CAS, Scopus and Google Scholar

- Research which is freely available for redistribution 